\title{
Anesthetic management of a 6 month-old infant for near total pancreatectomy with persistent hyperinsulinemic hypoglycemia
}

\author{
Seohui Ahn', Jeong Rim Lee ${ }^{1}$, Seok-Joo Han², and Hyunzu Kim ${ }^{1}$ \\ Departments of ${ }^{1}$ Anesthesiology and Pain Medicine, ${ }^{2}$ Surgery, Yonsei University College of Medicine, Seoul, Korea
}

Though persistent or recurrent hypoglycemia in infancy is a very rare condition, it can cause major neurological damage and lifelong handicaps. Prompt recognition, specific diagnosis, and aggressive treatment are therefore essential to prevent the progression of neurological damage. The most common cause of this condition is persistent hyperinsulinemic hypoglycemia of infancy (PHHI), a syndrome previously known by a variety of different descriptive names, including nesidioblastosis and PHHI [1].

This report focuses on perioperative management of infants with PHHI. Because even healthy infants are vulnerable to difficulties with glycemic control during perioperative periods, proper anesthetic management of patients with hyperinsulinemic hypoglycemia is particularly critical. In this report, the authors demonstrate and discuss perioperative anesthetic management of glycemic control in a 7-month-old infant with PHHI who underwent near-total pancreatectomy.

The patient was a $6 \mathrm{M} 27 \mathrm{D}$ old male with a history of convulsions beginning 3 months after his birth. Physical exam was normal, but the glucose levels $(36-234 \mathrm{mg} / \mathrm{dl})$ were uncontrollable in spite of sugar replacement treatment and feedings. Despite the hypoglycemia, the insulin level was normal $(3.04 \mu \mathrm{IU} / \mathrm{ml})$, but the insulin/glucose ratio was 7.6 (Normal range: $<0.4$ ). The patient was started on diazoxide treatment, which was continued for 6 days but was ineffective.

Other lab values, as well as studies including electroencephalogram (EEG), brain radiologic evaluation, echocardiography, and genetic assays were all normal, so PHHI was suspected, and the patient was scheduled for pancreatectomy.

In the operating room, the patient underwent induction of anesthesia with sevoflurane and rocuronium $(0.6 \mathrm{mg} / \mathrm{kg})$ and was intubated with an uncuffed tube (internal diameter $3.0 \mathrm{~mm}$ ). Anesthesia was maintained with oxygen and air (50:50 mixture), sevoflurane (0.7-1.0 MAC), and intermittent doses of rocuronium. The left radial artery was cannulated with a $24 \mathrm{G}$ angio-catheter, and other monitoring included electrocardiogram, pulse oximetry, capnography, and esophageal temperature.

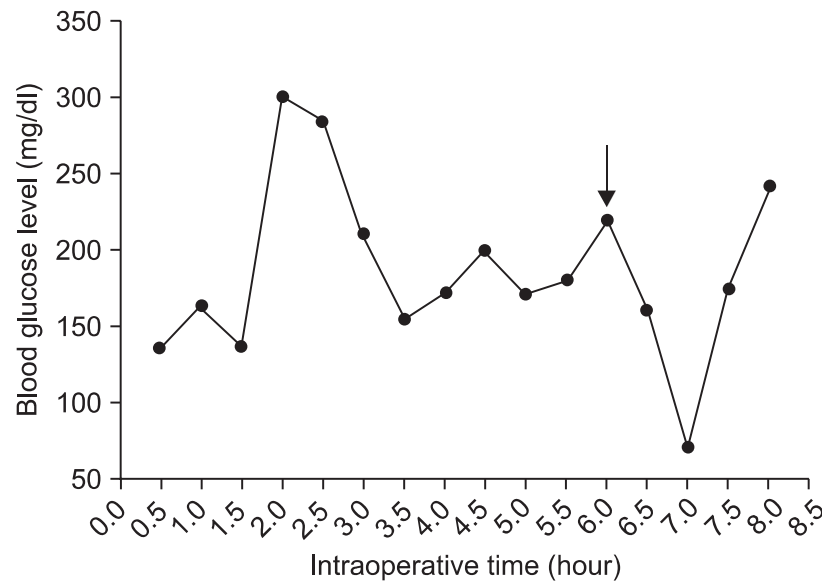

Fig. 1. Blood glucose levels measured every 30 minutes during the operation. The arrow shows the moment that the specimen is removed.

Corresponding author: Hyunzu Kim, M.D., Department of Anesthesiology and Pain Medicine, Yonsei University College of Medicine, 134, Shinchon-dong, Seodaemun-gu, Seoul 120-752, Korea. Tel: 82-2-2228-2427, Fax: 82-2-364-2951, E-mail: ANESHYUNZU@yuhs.ac

(c) This is an open-access article distributed under the terms of the Creative Commons Attribution Non-Commercial License (http:// creativecommons.org/licenses/by-nc/3.0/), which permits unrestricted non-commercial use, distribution, and reproduction in any medium, provided the original work is properly cited. 
After induction, a Broviac ${ }^{\circledR}$ catheter was inserted in the right internal jugular vein by the surgeon, and the operation was started. During the operation, $50 \mathrm{ml} / \mathrm{hr}$ of $10 \%$ dextrose solution was infused to prevent hypoglycemia, normal saline at a rate of $4 \mathrm{ml} / \mathrm{kg} / \mathrm{hr}$ was used as maintenance fluid, and Hartmann's solution at a rate of $10 \mathrm{ml} / \mathrm{kg} / \mathrm{hr}$ was used as replacement fluid. Estimated blood loss was $80 \mathrm{ml}$, so $50 \mathrm{ml}$ of packed red blood cells was transfused. The patient's blood glucose was analyzed every $30 \mathrm{~min}$, with a target blood glucose level of $80-180 \mathrm{mg} / \mathrm{dl}$ (Fig. 1). Immediately after removal of $95 \%$ of the pancreas, the $10 \%$ dextrose solution infusion was stopped.

At the end of the surgery we performed a blood gas analysis, also measuring blood glucose, which was $57 \mathrm{mg} / \mathrm{dl}$. Therefore, we slowly injected $20 \mathrm{ml}$ of $10 \%$ dextrose solution. The patient was extubated in the operating room when he was fully awake and breathing well. Emergence from anesthesia took about $40 \mathrm{~min}$, the total operation time was $5 \mathrm{hr} 30 \mathrm{~min}$, and the time under anesthesia was $7 \mathrm{hr} 10 \mathrm{~min}$.

Following extubation, the patient was transferred to the ICU. He was initially hyperglycemic, but this resolved spontaneously without any medication or intervention. After 1 day the patient's condition had stabilized, and he was transferred to the general ward.

The patient recovered fully, without complications, and was discharged on the 25th day post operation. His glucose level was well controlled $(95-268 \mathrm{mg} / \mathrm{dl})$ without medication for glucose control, and a follow-up EEG after 1 month was normal. The patient is now healthy, growing and feeding well.

PHHI patients need glucose infusion rates greater than 8 to $10 \mathrm{mg} / \mathrm{kg} / \mathrm{min}$ to maintain plasma glucose above $45 \mathrm{mg} / \mathrm{dl}$ after the first day of life, but radiologic studies provide no diagnostic explanation for this elevated requirement, such as a pancreatic tumor. When the diagnosis is established, diazoxide is generally administered for a few days to suppress insulin production.

Our goal during the operation and anesthesia was to maintain normoglycemia to mild hyperglycemia throughout the dynamic intraoperative period and the fluid shifts of major surgery.

First of all, we had to consider the effect of the type of anesthetic management or agent used. There was a report that the use of a combination of general anesthesia and epidural anesthesia reduced the glucose requirement during surgery, because that method can suppress the stress response to major surgery in infants [2]. However, we elected to perform only general anesthesia with sevoflurane because of technical difficulties and the possibility of massive bleeding. Additionally, most inhaled anesthetics, with the exception of desflurane, depress insulin release [3] and promote glucose intolerance
[4]. We therefore considered that performing only general anesthesia with sevoflurane would not significantly affect the blood glucose level of the infant in this study during anesthesia.

Our second concern was to avoid hypoglycemia during the operation; we therefore used both continuous infusion and bolus injections of $10 \%$ dextrose when the blood glucose level dropped below $60 \mathrm{mg} / \mathrm{dl}$, to maintain normoglycemia to moderate hyperglycemia. An additional consideration is that neonates and young children are susceptible to hypoglycemia due to immature ability of enzymatic glucose production and increased glucose requirements comparatively [5].

Finally, rebound hyperglycemia can occur after pancreatic mass excision, but it is transient, and in most cases resolves spontaneously after a few days, without intervention. In this case, a solution of $10 \%$ dextrose $4 \mathrm{ml} / \mathrm{kg} / \mathrm{hr}$ was infused to provide glucose until pancreatic mass removal, at which time the infusion was stopped. Hyperglycemic rebound following complete near-total pancreatectomy began 1 hour after the resection. Immediately following the operation, hypoglycemia appeared, and a $10 \%$ dextrose bolus injection was given to the patient. Within a few days after the surgery, the patient's glucose levels were well controlled without specific treatments.

In summary, pancreatecomy is semi-emergency surgery that is performed to protect the brain. It is a safe procedure that is well tolerated in infants and children, and successful anesthetic management depends on fluid management, to maintain normoglycemia in spite of changing glucose levels, and to maintain hemodynamic stability during the perioperative period. This procedure is always a challenge to many anesthesiologists.

\section{References}

1. Bellwoar C, Schwartz R, Stayer S. Anaesthetic management of a neonate with nesidioblastosis. Paediatr Anaesth 1996; 6: 61-3.

2. Mali M, Bagry H, Vas L. Anaesthetic management of a case of nesidioblastosis for subtotal pancreatectomy. Paediatr Anaesth 2002; 12: 80-4.

3. Thomas CG Jr, Underwood LE, Carney CN, Dolcourt JL, Whitt JJ. Neonatal and infantile hypoglycemia due to insulin excess: new aspects of diagnosis and surgical management. Ann Surg 1977; 185: 505-17.

4. Tanaka T, Nabatame H, Tanifuji Y. Insulin secretion and glucose utilization are impaired under general anesthesia with sevoflurane as well as isoflurane in a concentration-independent manner. J Anesth 2005; 19: 277-81.

5. Darmaun D, Haymond MW, Bier DM. Metabolic aspects of fuel homeostasis in the fetus and neonate. In: Endocrinology. 3rd ed. Edited by DeGroot LJ: New York, Grune and Stratton. 1993, pp 2258-82. 